\title{
CONFERÊNCIAS DE GRUPO FAMILIAR: PRÁTICAS RESTAURATIVAS COMO FERRAMENTAS DA PROTEÇÃO SOCIAL
}

\section{FAMILY GROUP CONFERENCES: RESTORATION PRACTICES AS TOOLS OF SOCIAL PROTECTION}

\author{
Mariane Leticia Pedroso Olegario* \\ Jussara Ayres Bourguignon*
}

\section{RESUMO}

Este artigo visa analisar como as Conferências de Grupo Familiar podem contribuir para proteção social dos sujeitos em situações de vulnerabilidade social. Para alcançar este objetivo, buscouse desenvolver uma pesquisa bibliográfica e documental, de caráter exploratório, tendo como marco referencial os autores Howard Zehr (2008; 2015), Allan Macrae (2020), Gosta EspingAndersen (1991), Célia Lessa Kertenetzky (2012) e Maria Carmelita Yazbek (2010). Inicialmente foram abordados os princípios e valores da Justiça Restaurativa, as peculiaridades das Conferências de Grupo Familiar e por fim foram tecidas reflexões sobre a relação entre estas e a proteção social. Destacou-se dentre os benefícios das Conferências de Grupo Familiar o fortalecimento dos vínculos comunitários e familiares, o empoderamento da família, mediante o resgate do poder de decidir e realizar as mudanças necessárias, e a maximização da provisão de recursos, bens e serviços sociais, por meio da articulação do sistema de justiça com a rede de proteção.

Palavras-chave: Justiça Restaurativa, sistema de proteção social, vulnerabilidade social.

\section{ABSTRACT}

This article aims to analyze how Family Group Conferences can contribute to the social protection of subjects in situations of social vulnerability. To achieve this goal, we sought to develop a bibliographic and documental research, of an exploratory nature, having as reference framework the authors Howard Zehr (2008; 2015), Allan Macrae (2020), Gosto Esping-Andersen (1991), Célia Lessa Kertenetzky (2012) and Maria Carmelita Yazbek (2010). Initially, the principles and values of Restorative Justice were addressed, the peculiarities of Family Group Conferences and, finally, reflections were made on the relationship between them and social protection. Among the benefits of Family Group Conferences, the strengthening of community and family bonds, the empowerment of the family, through the rescue of the power to decide and carry out the necessary changes, and the maximization of the provision of resources, goods and social services, stood out through the articulation of the justice system with the protection network.

Keywords: Restorative justice, social protection system, social vulnerability.

\footnotetext{
*Bacharel em Direito pela Universidade Estadual de Ponta Grossa. Especialista em Direito Processual Civil pela Universidade Estadual de Ponta Grossa. Mestre em Ciências Sociais Aplicadas pela Universidade Estadual de Ponta Grossa

"* Possui graduação em Serviço Social pela Universidade Estadual de Ponta Grossa (1984), Mestrado em Prática Profissional e Política Social pela Pontifícia Universidade Católica de São Paulo (1997) e doutorado em Serviço Social PUC/SP pela Pontifícia Universidade Católica de São Paulo (2005).
} 


\section{INTRODUÇÃO}

As Conferências de Grupo Familiar podem ser compreendidas como um tipo de reunião entre membros da família, da comunidade e da rede de apoio para tomada de decisões, realizada geralmente para proteger e resguardar os direitos dos vulneráveis. (CDHEP, 2019) A expressão "Grupo Familiar" é utilizada de forma ampla, visto que as famílias são plurais, com diferentes configurações e composições. Nessa concepção, compreende-se a família extensa, a comunidade, as pessoas que possuem alguma vinculação afetiva, alguma identificação cultural, ou ainda as pessoas que possam contribuir de alguma maneira para construção de um plano de ação.

Trata-se de uma metodologia da Justiça Restaurativa, que constitui um movimento social global, recomendado pela Organização das Nações Unidas (ONU) desde 1999, por meio da Resolução ${ }^{\circ} 26$ de 1999, intitulada "Desenvolvimento e implementação de medidas de mediação e justiça restaurativa na justiça criminal".

No Brasil as práticas restaurativas ainda são uma novidade, foram recepcionadas e regulamentadas pelo Poder Judiciário por meio da Resolução nº 225/2016 do Conselho Nacional de Justiça, que dispõe sobre a Política Nacional de Justiça Restaurativa. Elas não são executadas como alternativas ou substitutas ao sistema judicial, todavia vêm sendo cada vez mais incentivadas e gradativamente ofertadas pelos Tribunais.

As Conferências de Grupo Familiar ainda são pouco conhecidas e aplicadas no Brasil. De acordo com a pesquisa realizada pelo CNJ (2019), apenas 15,9\% dos Tribunais brasileiros utilizam esta metodologia e apenas 38,6\% dos Tribunais possuem interesse por curso e capacitação.

Além disso, há pouquíssimo material sobre a temática. A principal obra em língua portuguesa é uma tradução da Editora Palas Athena, com o título "Conferências de Grupos Familiares: Modelo da Nova Zelândia" dos autores Howard Zher e Allan MacRae. Ademais, ainda não há trabalhos acadêmicos desenvolvidos sobre o tema. Em pesquisa realizada junto a Biblioteca Nacional de Teses e Dissertações ${ }^{1}$ utilizando as expressões "Conferência de Grupo Familiar", "Conferências de Grupo Familiar" e "Conferências de Justiça Restaurativa" não foi encontrado nenhum trabalho, e o resultado foi o mesmo em pesquisa realizada junto ao banco de dados de Periódicos da CAPES ${ }^{2}$, utilizando as mesmas expressões. ${ }^{3}$

A escassez de materiais e pesquisas sobre a temática, aliada a incipiente utilização pelo Poder Judiciário, justificam o interesse na investigação das Conferências de Grupo Familiar, metodologia da Justiça Restaurativa que apresenta grandes potencialidades de aplicação, pois embora mais trabalhosa por envolver familiares, amigos e a rede de apoio, é mais vantajosa por obter soluções criativas, integrativas e adequadas a realidade social dos interessados.

Diante disso, o objetivo principal deste trabalho é analisar como as Conferências de Grupo Familiar podem, para além de tratar o crime e/ou conflito, contribuir para o enfrentamento das situações de vulnerabilidade social. Para alcançar este objetivo, busca-se descrever os fundamentos, princípios e valores da Justiça Restaurativa, caracterizar as Conferências de Grupo Familiar, bem

\footnotetext{
'Disponível no endereço eletrônico: https://bdtd.ibict.br/vufind/

2 Disponível no endereço eletrônico: https://www-periodicos-capes-gov-br.ezl.periodicos.capes.gov.br/

${ }^{3}$ Foram encontrados trabalhos na área da saúde com o tema "Conferência Familiar", um instrumento de intervenção e apoio às famílias dos pacientes em cuidados paliativos, que demandam a tomada de decisões, ou em situações de conflito. (NETO, 2003) Todavia, esta ferramenta dos profissionais da saúde não se confunde com a metodologia da Justiça Restaurativa, apresentada neste trabalho.
} 
como, contextualizar o sistema de proteção social brasileiro, ainda em processo de construção, de modo a tecer reflexões sobre as relações entre as conferências de grupo familiar e a proteção social.

Trata-se de uma pesquisa eminentemente teórica, de caráter exploratório, com fontes bibliográficas e documentais, que tem como marco teórico os autores Howard Zehr (2008; 2015; 2020), Allan Macrae (2020), Gosta Esping-Andersen (1991), Célia Lessa Kertenetzky (2012) e Maria Carmelita Yazbek (2010).

\section{PRINCÍPIOS E VALORES DAS PRÁTICAS RESTAURATIVAS}

A utilização da Justiça Restaurativa pelo sistema de justiça é recente, ocorreu a partir da década de 1970, porém sua origem remonta a práticas comunitárias ancestrais. (ZEHR, 2015) Portanto, não é algo novo, é um novo olhar para as tradições e para maneira de tratar e transformar conflitos, uma verdadeira "adequação cultural" no sistema de justiça. (DALY, 2001, p. 65)

O autor Howard Zehr (2015), um dos pioneiros na estruturação da Justiça Restaurativa, pontua que mais importante do que definir o que é Justiça Restaurativa, é estabelecer o que ela não é. Para o referido autor, a Justiça Restaurativa não tem como objeto principal o perdão ou a reconciliação; não é o mesmo que mediação; não tem por objetivo principal reduzir a reincidência; não é um programa ou projeto específico; não é aplicada somente a pequenas ofensas ou para ofensores primários; não é uma panaceia, nem um substituto para o processo penal; não é necessariamente uma alternativa ao aprisionamento; e também não se contrapõe necessariamente à justiça retributiva.

Partindo destas considerações, e reconhecendo as imprecisões conceituais do tema, adota-se neste trabalho a concepção de que a Justiça Restaurativa é um movimento social, que visa promover justiça envolvendo todos aqueles que foram afetados e possuem interesse no crime ou no conflito, "a fim de restabelecer as pessoas e endireitar as coisas". (ZEHR, 2015, p. 54) Deste modo, pode-se compreender a Justiça Restaurativa como um convite ao diálogo, a reparação e a responsabilização.

Apesar da amplitude e das imprecisões conceituais, a Justiça Restaurativa possui características fundamentais que a distinguem do modelo tradicional de justiça, pois tem foco nos danos e nas consequentes necessidades da vítima, do ofensor e da comunidade; trata das obrigações resultantes desses danos, tanto do ofensor quanto da comunidade; utiliza processos inclusivos e cooperativos, envolvendo todos que foram afetados e têm interesse na situação; e busca corrigir os males. (ZEHR, 2015)

Não há um consenso entre os autores quanto aos valores e princípios da Justiça Restaurativa. Vans Ness (2000) aponta três princípios e os quatro valores, os princípios são: 1) trabalhar para restaurar as vítimas, infratores e comunidades que foram feridas pelo crime; 2) as vítimas, infratores e comunidades devem ter oportunidades de envolvimento ativo no processo o mais cedo e plenamente possível; 3) o governo é responsável por preservar a ordem e a comunidade por estabelecer a paz, sendo ambos responsáveis pela promoção da justiça. E os valores são: o encontro; a reparação; a reintegração e a inclusão. Zehr (2012) aponta três princípios, considerados os pilares da Justiça Restaurativa: foco no dano cometido, obrigação de repará-lo, e engajamento ou participação dos afetados (vítima, ofensor e comunidade). Bianchini (2012 apud GRAF, 2019) indica seis princípios: voluntariedade, confidencialidade, celeridade, urbanidade, adaptabilidade e imparcialidade.

Em uma tentativa de uniformização, a Organização das Nações Unidas (ONU) por meio das Resoluções n 2000/14 e 2002/12 do Conselho Econômico e Social fixou os princípios fundamentais que devem orientar programas restaurativos em matéria criminal, mas que se estende para outras 
áreas. Dentre eles, destaca-se a voluntariedade, a confidencialidade, o tratamento igualitário, a imparcialidade, a subsidiariedade e a observância das garantias processuais.

No âmbito nacional, a Resolução n 225/2016, que dispõe sobre a Política Nacional de Justiça Restaurativa, prevê doze princípios: a corresponsabilidade, a reparação dos danos, o atendimento às necessidades de todos os envolvidos, a informalidade, a voluntariedade, a imparcialidade, a participação, o empoderamento, a consensualidade, a confidencialidade, a celeridade e a urbanidade. (CNJ, 2016) Ainda, a referida resolução estabelece que

A Justiça Restaurativa constitui-se como um conjunto ordenado e sistêmico de princípios, métodos, técnicas e atividades próprias, que visa à conscientização sobre os fatores relacionais, institucionais e sociais motivadores de conflitos e violência, e por meio do qual os conflitos que geram dano, concreto ou abstrato, são solucionados de modo estruturado na seguinte forma:

I - é necessária a participação do ofensor, e, quando houver, da vítima, bem como, das suas famílias e dos demais envolvidos no fato danoso, com a presença dos representantes da comunidade direta ou indiretamente atingida pelo fato e de um ou mais facilitadores restaurativos; II - as práticas restaurativas serão coordenadas por facilitadores restaurativos capacitados em técnicas autocompositivas e consensuais de solução de conflitos próprias da Justiça Restaurativa, podendo ser servidor do tribunal, agente público, voluntário ou indicado por entidades parceiras;

III - as práticas restaurativas terão como foco a satisfação das necessidades de todos os envolvidos, a responsabilização ativa daqueles que contribuíram direta ou indiretamente para a ocorrência do fato danoso e o empoderamento da comunidade, destacando a necessidade da reparação do dano e da recomposição do tecido social rompido pelo conflito e as suas implicações para o futuro. (CNJ, 2016, art. $\left.1^{\circ}\right)$

A Justiça Restaurativa pode ser aplicada a diferentes situações e contextos, de diferentes formas, desde que observados os valores e princípios restaurativos, que guardam a essência do processo de mudança na forma de tratar o crime ou o conflito. Segundo Zehr (2015) as principais metodologias utilizadas são os processos circulares, os encontros entre vítimas e ofensores, e as Conferências de Grupo Familiar.

No Brasil, os círculos de construção de paz constituem a técnica predominante, adotada em 93\% dos Tribunais, enquanto os encontros entre vítimas-ofensores ${ }^{4}$ são adotados em $25 \%$ dos Tribunais e as Conferências de Grupos Familiares em apenas 15,9\% dos Tribunais, conforme mapeamento realizado pelo CNJ (2019).

Para compreender estes dados, importante tecer algumas considerações. A primeira delas refere-se a introdução e a implementação da Justiça Restaurativa no Brasil, de forma vertical e institucionalizada, a partir da iniciativa de magistrados interessados pelo tema que buscaram por capacitação. Os primeiros cursos de Justiça Restaurativa no Brasil foram ministrados por Howard Zehr e por Kay Pranis, sendo esta a responsável pela sistematização dos círculos de construção de paz, prática de ampla aplicabilidade. Estes fatores evidentemente contribuíram para que os círculos de construção de paz se tornassem a prática dominante no país. (GOMES, GRAF, 2020)

Diferentemente dos círculos de construção de paz que podem ser aplicados em todas as searas, os encontros vítimas-ofensores são voltados a justiça criminal. Esta técnica iniciada em meados dos anos de 1970 nos Estados Unidos com a denominação de Programas de Reconciliação Vitima-Ofensor

${ }^{4}$ Os encontros vítima-ofensor, originalmente denominados de Programas de Reconciliação Vitima-Ofensor (Victim Offender Reconciliation Programs - VORP), também são referenciados pelos termos "conferências" ou "mediações". 
(Victim Offender Reconciliation Programs - VORP) visa "assistir vítimas e ofensores no processo de lidar com os aspectos relacionais do crime" (AMSTUTZ, 2019, p. 17).

Os encontros vítima-ofensor são realizados com o objetivo de oportunizar à vítima um espaço seguro para contar sua história, seus sentimentos, suas necessidades e buscar respostas, bem como, oportunizar ao ofensor um espaço seguro para contar o que aconteceu, assumir a responsabilidade pelos danos causados e ouvir o quanto estes afetaram a vida da vítima. (AMSTUTZ, 2019)

As Conferências de Grupo Familiar, por sua vez, com menor índice de aplicação nos Tribunais brasileiros, em comparação com os círculos de construção de paz e os encontros vítima-ofensor, podem ser aplicadas em todas as searas, mas geralmente são utilizadas em situações de crimes ou conflitos que envolvam pessoas vulneráveis, como crianças, adolescentes, idosos e deficientes.

Embora revelado no mapeamento realizado pelo CNJ (2019) a pequena aderência e interesse do Poder Judiciário por esta metodologia, a análise dos dados requer cautela e um olhar crítico. $\mathrm{O}$ percentual pode ser muito maior, tendo em vista que há confusão entre as práticas restaurativas, ocorrendo por vezes a aplicação de uma prática como se fosse outra, a combinação de metodologias e até mesmo a denominação equivocada. Conforme observado em pesquisa anterior do CNJ (2018), apesar de alguns servidores informarem a realização de círculos de construção de paz, os pesquisadores verificaram que em verdade eram realizadas conferências.

Estas diferentes metodologias encontram nos princípios e valores restaurativos similaridade, sendo incontestáveis as potencialidades de cada uma delas para transformar os conflitos. Todavia, sendo o enfoque deste trabalho as Conferências de Grupo Familiar, destaca-se o potencial ainda maior desta metodologia, que embora mais trabalhosa por envolver os familiares e a rede de apoio e proteção dos interessados, alcança soluções criativas, integrativas e adequadas, capazes de promover significativas mudanças, conforme será exposto no próximo tópico.

\section{AS CONFERÊNCIAS DE GRUPO FAMILIAR}

As Conferências de Grupo Familiar têm origem nas reivindicações dos povos nativos da Nova Zelândia, chamados Maori. Na tradição Maori a justiça deve buscar a reparação e não somente a punição, pois tanto a vítima quanto o ofensor precisam da cura, e descobrir a causa da ofensa faz parte da solução. (MACRAE, 2020)

A Nova Zelândia enfrentou uma crise no sistema de justiça juvenil, que estava sobrecarregado, com muitas crianças e adolescentes Maori em instituições de acolhimento e em encarceramento. As autoridades reconheceram que o sistema de justiça ocidental não era culturalmente adequado, então buscaram elementos da cultura Maori para solucionar o problema. (DALY, 2001)

Então, em 1989 foi aprovada a Lei das Crianças, Jovens e Suas Famílias, que modificou completamente o sistema de justiça juvenil do país, colocando a Conferência de Grupo Familiar como eixo central do sistema de justiça juvenil. (MACRAE, 2020) Com isso, a Nova Zelândia se tornou uma referência e as Conferências de Grupo Familiar se expandiram para Austrália, Ásia, África do Sul, América do Norte e Europa, que também desenvolveram seus modelos.

Na lei neozelandesa, todos os casos graves envolvendo crianças e adolescentes, com exceção dos crimes de homicídio doloso e culposo, devem ser encaminhados para uma Conferência de Grupo Familiar, de tal modo que o sistema judicial passou a ser subsidiário. (MACRAE, 2020) 
Para Daly (2001) a Conferência de Grupo Familiar é uma resposta tanto de justiça, quanto de bem-estar, que foi incorporada em uma estrutura legislativa, na Nova Zelândia, que efetivamente se preocupa e busca proteger as crianças.

De acordo com o Centro de Direitos Humanos e Educação Popular de Campo Limpo ${ }^{5}$ a Conferência de Grupo Familiar desenvolve-se como uma reunião mediada entre os membros de uma família, com a participação de profissionais e técnicos de diferentes áreas para orientar e esclarecer eventuais dúvidas, com o objetivo de formular um plano de ação. (CDHEP, 2019)

Não há um roteiro preestabelecido para aplicação das Conferências de Grupo Familiar, elas podem e devem ser adaptadas à cultura e tradição do local onde serão desenvolvidas para que alcancem soluções adequadas.

No entanto, para orientar a prática, o autor Allan MacRae (2020) apresenta um guia, inspirado no modelo pioneiro da Nova Zelândia, com cinco passos. O primeiro deles é a abertura, que começa com o acolhimento dos participantes e uma cerimônia de boas-vindas, seguida das apresentações pessoais e da metodologia. Todos os participantes precisam ter ciência de como vai funcionar o procedimento e quais os princípios o orientam. O passo seguinte é da partilha das informações, com a exposição do resumo dos fatos pelos facilitadores/coordenadores, o relato da vítima, a visão do ofensor e a manifestação de cada um dos participantes. Neste momento são realizadas perguntas e passadas as orientações técnicas para elaboração do plano. Podem ser convidados profissionais especializados, para esclarecer as dúvidas que possam surgir durante a elaboração do plano. Na sequência, é oportunizada a reunião privada entre os membros da família, os quais com liberdade e autonomia poderão dialogar e deliberar sobre propostas para um acordo. Esta reunião é bastante importante para aproximar a família, que muitas vezes precisa lidar com questões intrafamiliares primeiramente. A elaboração do acordo é o quarto passo e o ponto chave das Conferências de Grupos Familiares, neste momento discutem-se as propostas, todos participam das negociações e após o consenso, ou seja, a concordância de todos os participantes, ocorre a finalização do plano. Por último, os facilitadores realizam o encerramento, com uma cerimônia de agradecimento ou de despedida. (MACRAE, 2020)

No Brasil, o Centro de Direitos Humanos e Educação Popular de Campo Limpo desenvolveu um fluxograma do procedimento, o qual é reproduzido a seguir:

\footnotetext{
${ }^{5}$ Organização não governamental que tem como objetivo promover estratégias de formação, articulação, comunicação e incidência em políticas públicas para prevenir e superar as diversas formas de violência existentes nas periferias. Para mais informações, acesse o endereço eletrônico: https://cdhep.org.br/.
} 


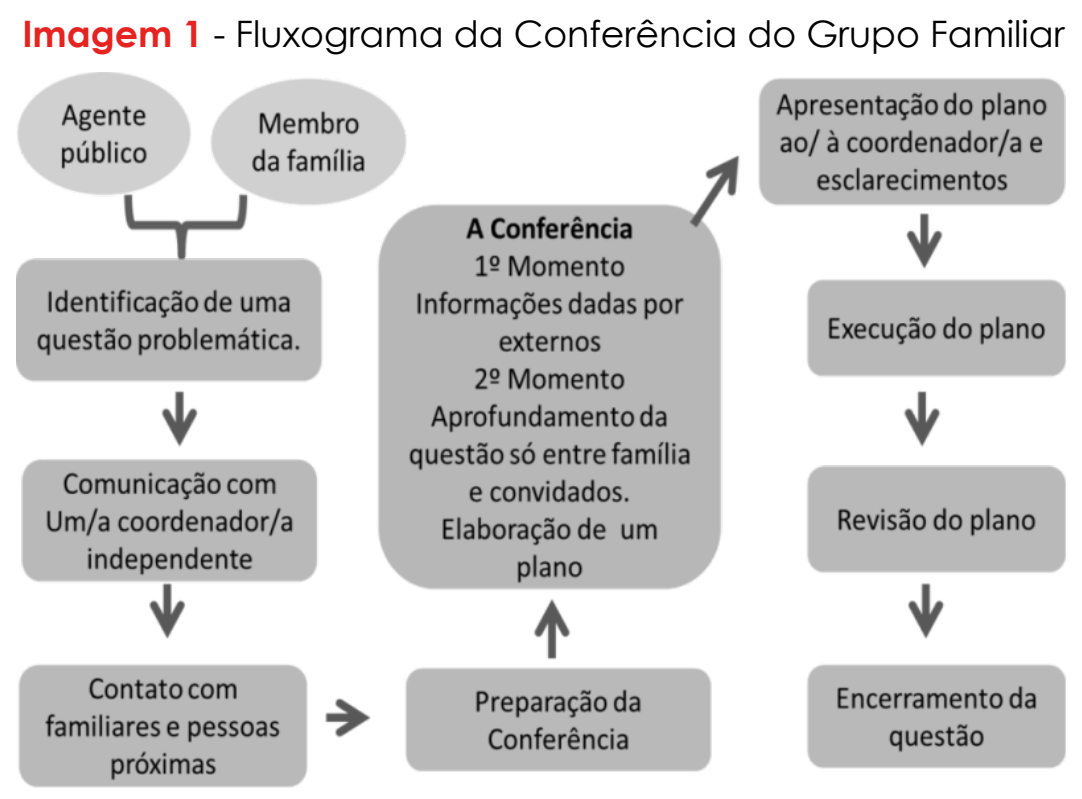

Fonte: CDHEP, 2019.

O fluxograma apresentado é meramente sugestivo, considerando que não há um roteiro preestabelecido, mas contempla as principais etapas da metodologia.

Conforme consta na imagem, o procedimento pode ser iniciado voluntariamente por algum membro da família ou pelo Poder Público, nesse caso geralmente advém de um encaminhamento do Poder Judiciário, do Ministério Público, dos serviços da rede socioassistencial, como CRAS e CREA, serviços de saúde, de acolhimento institucional, socioeducativo ou penitenciário.

O responsável por organizar o procedimento é o facilitador, quem também cuida da preparação, momento no qual conversa individualmente com cada um dos participantes para conhecer suas necessidades, interesses, sentimentos e percepções sobre o conflito. No momento da Conferência o facilitador tem o dever de facilitar o diálogo e não participa substantivamente das discussões. (DALY, 2001)

Para orientar a todos os envolvidos, o facilitador pode convidar técnicos para repassar informações importantes sobre o assunto discutido e realizar os encaminhamentos necessários, de modo a dar condições para os participantes decidirem o que é preciso para o ofensor reparar o dano, como será feito isso e que assistência o ofensor precisará para isso. (DALY, 2001)

A reunião privada da família e a construção coletiva do plano são os pontos altos da metodologia. A Justiça Restaurativa proporciona um espaço seguro para o diálogo e por meio da Conferência de Grupo Familiar a família tem a oportunidade de conversar sobre algo que afetou a todos, direta ou indiretamente, e que precisa ser reparado, da melhor maneira possível.

O plano precisa ser claro, objetivo e contemplar a reparação, a responsabilização, o papel de cada um dos envolvidos, os prazos e expectativas. MacRae (2020) sugere a elaboração do plano em quatro partes. A primeira parte para abordar questões sistêmicas, processuais, por exemplo, sobre quais pontos foram decididos, se deverá ser homologado pelo juiz. A segunda parte para registrar a reparação, como o ofensor irá corrigir o mal causado a vítima e a comunidade, como a família se comprometerá. A terceira, destinada a tratar da prevenção, aborda as causas subjacentes que contribuíram para ocorrência do crime ou conflito e inclui encaminhamentos para tratamento psicológico, 
por exemplo. A quarta e última etapa é voltada para o monitoramento, como será acompanhada a execução do plano, como será mantido o contato e repassadas as informações a respeito.

Para o sucesso da Conferência de Grupo Familiar é importante que a execução do plano seja monitorada e caso necessário seja realizada uma nova reunião, com todos os participantes, com a finalidade de revisar e adequar o plano, para torná-lo factível. Após a execução também é interessante realizar uma reunião com todos os participantes para avaliar e encerrar a questão.

Compreender como funciona a Conferência de Grupo Familiar possibilita enxergar as potencialidades desta metodologia, que propõe reunir os interessados no crime/conflito, juntamente com seus familiares e a comunidade, para receberem informações, dialogarem e juntos elaborarem um plano de ação voltado a reparação dos danos, possibilitando uma verdadeira responsabilização do ofensor.

Daly (2001) cita uma pesquisa realizada em 1995, pelo projeto Re-Integrative Shaming Experiments (RISE) ${ }^{6}$, que buscou investigar o impacto da abordagem restaurativa por meio da percepção das vítimas e dos ofensores após participarem de Conferências de Grupo Familiar, e os resultados apontaram que as conferências oferecem uma melhor percepção de justiça do que o modelo tradicional, exercido pelos Tribunais, destacando que:

- Os ofensores relataram maior justiça processual (definida como sendo tratados de forma justa e com respeito) em conferências do que no tribunal.

- Os ofensores relataram níveis mais elevados de justiça restaurativa (definida como oportunidade de reparar o dano que causaram) em conferências do que no tribunal.

- As conferências, mais do que o tribunal, aumentaram o respeito dos infratores pela polícia e a lei.

- O senso de justiça restaurativa das vítimas é maior para aqueles que foram a conferências em vez do tribunal (definido como, por exemplo, recuperação da raiva e constrangimento). (STRANG et al, 1999; STRANG, 1999 apud DALY, 2001, p. 73)

Além do senso de justiça e da satisfação proporcionada pela prática restaurativa, as Conferências de Grupo Familiar apresentam vários benefícios. Destaca-se o fortalecimento dos vínculos familiares, geralmente fragilizados pelo conflito ou ofensa, uma vez que não somente as pessoas, mas também os relacionamentos são afetados. Destaca-se também a maximização da provisão de recursos, bens e serviços sociais, por meio da assistência oferecida ao ofensor e aos afetados pelo crime/conflito. O resultado restaurativo é uma resposta de justiça, que não é completa sem garantir o bem-estar dos envolvidos.

Outro benefício das Conferências de Grupo Familiar é o empoderamento dos participantes e da família. Com base em Paulo Freire, compreende-se a pessoa, grupo ou instituição empoderada como "aquela que realiza, por si mesma, as mudanças e ações que a levam a evoluir e se fortalecer". (VALOURA, 2005/2006, p.2) Está relacionado ao processo de assumir o poder, em quatro dimensões: "cognitiva (visão crítica da realidade), psicológica (sentimento de auto-estima), política (consciência das desigualdades de poder e a capacidade de se organizar e mobilizar) e a econômica (capacidade de gerar renda independente)" (NELLY STROMQUIST apud BERTH, 2018, p. 232)

Todavia, alcançar os benefícios apontados requer que os envolvidos consigam cumprir os compromissos assumidos no plano, e caso não consigam, recebam a assistência necessária para enfrentar as situações de fragilidade, para então alcançar o resultado restaurativo.

${ }^{6}$ Além dessa pesquisa, a autora apresenta outras pesquisas desenvolvidas para avaliar o impacto das Conferências de Grupo Familiar na Nova Zelândia e na Austrália. 


\section{REFLEXÕES SOBRE AS CONFERÊNCIAS DE GRUPO FAMILIAR E A PROTEÇÃO SOCIAL}

O plano construído na Conferência de Grupo Familiar é resultado do diálogo, da criatividade e do consenso universal daqueles que conhecem e querem o melhor para a vítima e para o ofensor. Ele é fruto do reconhecimento da família sobre suas próprias necessidades, possibilidades e fragilidades, bem como, do reconhecimento das questões subjacentes que contribuíram para ocorrência do conflito.

Tais aspectos nem sempre são considerados ou recebem atenção do modelo tradicional de justiça. Embora seja

[...] óbvio mencionar a importância de se perguntar como a própria família define seus problemas, suas necessidades, seus anseios e quais são os recursos de que ela mesma dispõe. Menos óbvio é pensar como ouvimos suas respostas e o estatuto que atribuímos ao que se diz. (SARTI, 2015, p. 45).

A Justiça Restaurativa, especialmente as Conferências de Grupo Familiar, se propõe em ouvir os interesses e as necessidades da família, permitir que ela seja protagonista, tenha autonomia e condições de decidir sobre seus problemas, apoiar e acolher os seus perante as adversidades.

No entanto, para que o resultado restaurativo seja alcançado, a família precisa ser protegida pelo Estado. Precisa ter acesso aos recursos, bens e serviços sociais necessários, como educação, assistência social, saúde, habitação, trabalho, cultura, lazer, entre outros, para cumprir com suas funções básicas, quais sejam: garantir a "proteção e a socialização dos seus membros; constituir-se como referências morais, de vínculos afetivos e sociais; de identidade grupal, além de ser mediadora das relações dos seus membros com outras instituições sociais e com o Estado." (BRASIL, 2005)

Segundo Di Giovanni (1998) entende-se por proteção social as formas "institucionalizadas que as sociedades constituem para proteger parte ou o conjunto de seus membros. Tais sistemas decorrem de certas vicissitudes da vida natural ou social, tais como a velhice, a doença, o infortúnio, as privações".

Para compreender melhor a proteção social, remete-se ao surgimento do Estado de Bem-Estar Social, após o contexto das grandes guerras, quando o Estado passou a se preocupar em proteger os indivíduos contra as contingências que impedem de prover suas necessidades. O Estado de Bem-Estar Social assumiu a proteção social como direito dos cidadãos, todavia em diferentes níveis, conforme os contextos históricos, políticos e econômicos específicos.

Deste modo, foram reconhecidos três modelos de regime de bem-estar social, classificados segundo Titmuss de acordo com as prioridades políticas, sendo eles: o residual, o industrial e institucional ou corporativo. No primeiro, o gasto social é baixo e as políticas sociais são seletivas, o Estado atua quando a família e o mercado não tem uma resposta às necessidades individuais. O segundo é baseado no mérito, no desempenho do trabalho e da produtividade, o Estado atua para garantir o desenvolvimento econômico. Por fim, o terceiro regime baseia-se nas necessidades sociais, sendo o gasto social e as políticas sociais robustas, o Estado provê serviços básicos de formal universal. (KERSTENETZKY, 2012)

A partir desses três eixos, Esping-Andersen (1991) desenvolveu um estudo comparativo dos tipos de Estados de Bem-Estar Social implementados em diferentes países. O autor define Estado do Bem-Estar Social "como a personificação de uma determinada economia política" e classifica três regimes de bem-estar: o liberal (laissez-faire), o conservador-corporativo e o social-democrata. 
No regime liberal o papel central é ocupado pelo mercado, atuando o Estado de forma subsidiária, assim, a assistência social é limitada e temporária, destinada somente aos necessitados. No regime Conservador-Corporativo o Estado atua por meio da seguridade social, visando garantir o pleno emprego, os gastos públicos advêm de contribuições obrigatórias dos trabalhadores e as estes são direcionados. Por sua vez, no regime social-democrata o Estado assume o papel central, atua de forma universal e generosa, garantido direitos sociais abrangentes, que vão além das pensões e aposentadorias, compreendem também auxílios acidente e doença, seguro-desemprego, benefícios para famílias, entre outros. (ESPING-ANDERSEN, 1991)

Embora identificados diferentes modelos e regimes, o Estado de Bem-Estar caracterizou-se pela responsabilidade, às vezes maior, às vezes menor, do Estado pelo bem-estar de seus membros (YAZBEK, 2010).

No Brasil, é possível reconhecer três ondas de proteção social: os anos de bem-estar corporativo, entre 1930 e 1964, período de implementação das legislações trabalhistas e previdenciárias; o período de universalismo básico, entre os anos 1964 e 1984, que estendeu a proteção a estratos sociais tradicionalmente excluídos; e o período de universalismo estendido, após a Constituição Federal de 1988, com a fixação de um mínimo social e um extenso rol de direitos fundamentais. (KERSTENETZKY, 2012, p.181)

A Constituição Federal de 1988 estabeleceu um sistema universal de seguridade social, estendendo a toda população o direito à previdência social, à saúde e à assistência social. O artigo 194 da Constituição define a seguridade social como um "conjunto integrado de ações de iniciativa dos Poderes Públicos e da sociedade, destinadas a assegurar os direitos relativos à saúde, à previdência e à assistência social". Consolidou-se assim um sistema formal de proteção social, com o objetivo de garantir aos cidadãos: "segurança de sobrevivência (de rendimento e de autonomia); de acolhida; de convívio ou vivência familiar". (BRASIL, 2005)

No âmbito da Política de Assistência Social, um dos objetivos elencados pela Constituição é a proteção à família (art. 203, inciso I), a qual é operacionalizada por meio de dois tipos de serviços:

I - Proteção Social Básica: conjunto de serviços, programas, projetos e benefícios da assistência social que visa a prevenir situações de vulnerabilidade e risco social por meio do desenvolvimento de potencialidades e aquisições e do fortalecimento de vínculos familiares e comunitários;

II - Proteção Social Especial: conjunto de serviços, programas e projetos que tem por objetivo contribuir para a reconstrução de vínculos familiares e comunitários, a defesa de direito, o fortalecimento das potencialidades e aquisições e a proteção de famílias e indivíduos para o enfrentamento das situações de violação de direitos (BRASIL, 2011, art. $\left.6^{\circ}-\mathrm{A}\right)$.

Contudo, como bem pontuou Aldaíza Sposati (2019) "ter um modelo brasileiro de proteção social não significa que ele já exista ou esteja pronto, mas que ele é uma construção que exige muitos esforços de mudanças." Apesar da promessa constitucional, a formação histórica da sociedade brasileira, marcada pela experiência colonial, bem como, o atual cenário político e econômico, não contribuíram para efetiva universalização da seguridade social, de modo que o acesso a bens e serviços sociais caracteriza-se por ser desigual, heterogêneo e fragmentado. (YAZBEK, 2010)

Em razão disso, muitas famílias brasileiras enfrentam situações de vulnerabilidade social, compreendida de forma ampla, como todas as situações que fragilizam os indivíduos, decorrentes da 
pobreza, do precário ou nulo acesso aos serviços públicos, e/ou da fragilização de vínculos afetivos, relacionais e de pertencimento social (discriminações etárias, étnicas, de gênero ou por deficiências, dentre outras). (BRASIL, 2005).

A vulnerabilidade social não possui um conceito unívoco, é multifacetada e deve ser observada em suas múltiplas manifestações na realidade do cidadão. Para os fins deste trabalho observa-se que tais manifestações, para além das condições de pobreza da população

[...] abarcam, igualmente, vitimizações, fragilidades e contingências que o cidadão, a cidadã e suas famílias enfrentam na trajetória de seu ciclo de vida, em decorrência de imposições sociais, econômicas e políticas.

Assim compreendidas, as vulnerabilidades sociais vinculam-se a situações de empobrecimento da classe trabalhadora, relacionadas a dificuldades materiais para a manutenção da sobrevivência, mas, também, a dificuldades relacionais e culturais, pois estas interferem na forma de viver dos trabalhadores e de suas famílias. Tais situações se manifestam de acordo com o ciclo vital das famílias dos usuários da política de assistência social, em diferentes territórios onde habitam. (SEMZEZEM e ALVES, 2013, p. 144)

A proteção social, no âmbito da Política de Assistência Social implica em garantias aos cidadãos em situação de vulnerabilidade e/ou risco social, as quais são: segurança de acolhida; segurança de renda; segurança de convívio social, familiar e comunitária; segurança de desenvolvimento de autonomia individual, familiar e social e segurança de sobrevivência a riscos circunstanciais. (BRASIL, 2005). Para tanto, é necessário a oferta de serviços, programas e projetos que oportunizem o desenvolvimento de ações que promovam o conjunto das seguranças preconizadas na política.

Neste sentido, as Conferências de Grupos Familiares, podem servir de instrumento para o enfrentamento destas situações de vulnerabilidade social, a medida que promovem o fortalecimento dos vínculos familiares, o empoderamento da família e a maximização da provisão de recursos, bens e serviços sociais, por meio da articulação com a rede de proteção.

Conforme explicitado anteriormente, a dinâmica da Conferência de Grupo Familiar oferece aos envolvidos as orientações técnicas pertinentes para esclarecimento da situação e conta com a participação de profissionais das diferentes áreas do conhecimento que compõe a rede de apoio e de proteção dos interessados.

Trata-se de um momento estratégico de articulação entre as políticas públicas, fundamental para materialização da proteção social, que converge com as orientações programáticas do CNJ, previstas na Resolução no 225/2016, de aplicação da Justiça Restaurativa em caráter intersetorial, ou seja, "em colaboração com as demais políticas públicas, notadamente segurança, assistência, educação e saúde" (Art. $3^{\circ}$, inciso V).

Conforme apontado por Orth (2019), atendendo à diretriz de intersetorialidade, os profissionais e facilitadores envolvidos nas práticas restaurativas tem a oportunidade de levantar as demandas sociais dos participantes e através da articulação com a rede de serviços destinados à proteção social potencializar o acesso destes cidadãos aos programas, projetos, serviços e benefícios sociais, que propiciam o desenvolvimento de habilidades e condições para superar as situações de vulnerabilidades, exercitando a cidadania e garantindo seus direitos. 


\section{CONSIDERAÇÕES FINAIS}

As Conferências de Grupos Familiares constituem práticas restaurativas de origem ancestral, utilizadas em diferentes contextos para tomada de decisões, especialmente em situações que envolvem pessoas vulneráveis, como crianças, adolescentes, idosos e deficientes.

Desenvolvem-se como uma reunião conduzida pelo coordenador/facilitador, com a participação de profissionais e técnicos de diferentes áreas que realizam orientações, entre os interessados no conflito ou na ofensa, juntamente com os membros da família, com o objetivo de formular um plano de ação, que contemple a reparação dos danos, a responsabilização do ofensor e o compromisso dos envolvidos.

Dentre os benefícios da metodologia ainda pouco conhecida e aplicada no Brasil, destacou-se o fortalecimento dos vínculos familiares e comunitários, a maximização da provisão de recursos, bens e serviços sociais e o empoderamento dos indivíduos e da família, mediante o resgate do poder de decidir e realizar, por si própria, as mudanças necessárias.

A prática é considerada bem-sucedida quando o procedimento é conduzido adequadamente, conforme os princípios e valores da Justiça Restaurativa, e o plano é integralmente cumprido pelos envolvidos, atingindo-se a reparação dos danos e a respectiva responsabilização.

Para alcançar o resultado restaurativo, a família precisa ter condições de apoiar e acolher os seus, precisa ter acesso aos recursos, bens e serviços sociais fundamentais, como educação, assistência social, saúde, habitação, cultura, lazer, trabalho, entre outros, para cumprir os compromissos assumidos no plano.

A família demanda a proteção do Estado, o qual é responsável pelo bem-estar dos cidadãos e pela promoção da segurança contra as vicissitudes da vida natural ou social, tais como a velhice, a doença, o infortúnio, as privações de renda, bens e serviços públicos.

A Constituição Federal de 1988 estabeleceu um sistema universal de seguridade social, estendendo a toda população o direito à previdência social, à saúde e à assistência social, consolidando assim um sistema formal de proteção social, que ainda não se materializou completamente. A formação histórica da sociedade brasileira, aliada ao atual cenário político e econômico do país, não contribuíram para efetiva universalização da proteção social.

As situações de vulnerabilidade social, decorrentes da pobreza, discriminação, violência, da inserção precária ou não inserção no mercado de trabalho formal e informal, da perda ou fragilidade de vínculos de afetividade, pertencimento e sociabilidade, entre outras, fragilizam e dificultam o alcance do resultado restaurativo.

Deste modo, as Conferências de Grupo Familiar, além de configurar uma metodologia de transformação e prevenção de conflitos, constituem instrumentos de enfrentamento das situações de vulnerabilidade social a medida que promovem o fortalecimento dos vínculos familiares e comunitários, o empoderamento da família e a maximização da provisão de recursos, bens e serviços sociais, por meio da articulação do sistema de justiça com a rede de proteção. 


\section{REFERÊNCIAS}

AMSTUTZ, Lorraine Stutzman. Encontros vítima-ofensor: reunindo vítimas e ofensores para dialogar. Tradução: Tonia Van Acker. São Paulo: Palas Athena, 2019.

BERTH, Joice. O que é empoderamento? Belo Horizonte (MG): Letramento, 2018.

BRASIL. Constituição (1988). Constituição da República Federativa do Brasil. Promulgada em 05 de Outubro de 1988. Disponível em: <http://www.planalto.gov.br/ccivil_03/constituicao/constituicao. htm>. Acesso em: 11 jun 2021.

BRASIL. Concepção de convivência e fortalecimento de vínculos. Ministério do Desenvolvimento Social, Secretaria Nacional de Assistência Social. Brasília, 2017. Disponível em: <http://www.mds. gov.br/webarquivos/publicacao/assistencia_social/Cadernos/concepcao_fortalecimento_ vinculos.pdf>. Acesso em: 11 jun 2021.

BRASIL. Lei n 12.435. Altera a Lei n 8.742, de 7 de dezembro de 1993, que dispõe sobre a organização da Assistência Social. Diário Oficial da União, Brasília, 06 de julho de 2011 . Disponível em: <http://www.planalto.gov.br/ccivil_03/constituicao/ constituicao.htm>. Acesso em: 11 jun 2021.

BRASIL. Política Nacional de Assistência Social. PNAS/2004. Ministério do Desenvolvimento Social e Combate à Fome, Secretaria Nacional de Assistência Social. Brasília, 2005. Disponível em: <https:// www.mds.gov.br/webarquivos/publicacao/assistencia_social/Normativas/PNAS2004.pdf> . Acesso em: 11 jun 2021.

CDHEP - CENTRO DE DIREITOS HUMANOS E EDUCAÇÃO POPULAR DE CAMPO LIMPO. Prática Restaurativa Conferência do Grupo Familiar. São Paulo, 2019. Disponível em: <www.cohep.org.br>. Acesso em: 07 out 2020.

CONSELHO NACIONAL DE JUSTIÇA. Relatório Analítico Propositivo - Justiça Pesquisa. Pilotando a Justiça Restaurativa: o papel do Poder Judiciário. Presidente Ministra Cármen Lúcia Antunes Rocha, 2018. Disponível em: http://www.cnj.jus.br/files/conteudo/ arquivo/2018/04/7697d7ac45798202245f16ac41ddee76.pdf. Acesso em: 04 jun. 2020.

CONSELHO NACIONAL DE JUSTIÇA. Mapeamento dos Programas de Justiça Restaurativa. Presidente: Ministro José Antonio Dias Toffoli. Brasília: CNJ, 2019. Disponível em: <https://www.cnj.jus. br/wp-content/uploads/conteudo/arquivo/2019/06/8e6cf55c06c5593974bfb8803a8697f3>. Acesso em: 04 jun. 2020.

CONSELHO NACIONAL DE JUSTIÇA. Resolução 225, de 31 de maio de 2016. Dispõe sobre a Política Nacional de Justiça Restaurativa no âmbito do Poder Judiciário e dá outras providências. Disponível em: <https://atos.cnj.jus.br/atos/detalhar/2289>. Acesso em: 11 jun 2021.

DALY, Kathleen. Conferencing in Australia and New Zealand. In: MORRIS, Alisson; MAXWELL, Gabrielle (Orgs). Restorative Justice for Juveniles: conferencing, mediation and circles. Hart Publishing, Oxford - Portland Oregon, 2001, p. 59-83.

DI GIOVANNI, Geraldo. Sistemas de Proteção Social: uma introdução conceitual. In Reforma do Estado e Políticas de Emprego no Brasil. Campinas/SP, UNICAMP, 1998.

ESPING-ANDERSEN, Gosta. As três economias políticas do welfare state. Lua Nova, São Paulo , n. 24, p. 85-1 16, Set. 1991. Disponível em: <https://www.scielo.br/j/In/a/99DPRg4vVqLrQ4XbpBRHc5H/? lan $\mathrm{g}=\mathrm{pt}>$. Acesso em: 11 jun. 2021. 
GOMES, Jurema Carolina da Silveira; GRAF, Paloma Machado. Círculo de construção de paz no Brasil: uma prática dominante. In: ORTH, Glaucia Mayara Niedermeyer ; GRAF, Paloma Machado. Sulear a justiça restaurativa: as contribuições latino-americanas para a construção do movimento restaurativo. Coleção Singularis, v.8. [livro eletrônico]. Ponta Grossa: Texto e Contexto, 2020. cap. 5, p. 98-125. Disponível em: <https://www.textoecontextoeditora.com.br/ assets/uploads/ arquivo/8bc9f-ebook-sulear-a-justica-restaurativa.pdf>. Acesso em: 21 mar. 2021.

KERTENETZKY, Célia Lessa. O Estado de Bem-Estar na Idade da Razão. Rio de Janeiro: Campus, 2012.

MACRAE, Allan. ZHER, Howard. Conferências de Grupos Familiares: modelo da Nova Zelândia. Tradução: Fátima de Bastiani. São Paulo: Palas Athena, 2020.

NETO, Isabel Galriça. A conferência familiar como instrumento de apoio à família em cuidados paliativos. Revista Portuguesa de Medicina Geral e Familiar, [S.I.], v. 19, n. 1, p. 68-74, jan. 2003. ISSN 2182-5181. Disponível em: <https://www.rpmgf.pt/ojs/ index.php/rpmgf/article/view/9906>. Acesso em: 21 mar 2021.

ORTH, Glaucia Mayara Niedermeyer. A justiça juvenil restaurativa e a rede de proteção social brasileira no atendimento a adolescentes autores de ato infracional em contexto de vulnerabilidade social. Tese. Programa de Pós-Graduação em Ciências Sociais Aplicadas. Universidade Estadual de Ponta Grossa - Paraná. Ponta Grossa, 2019.

SARTI, Cynthia. Famílias enredadas. In: Família: redes, laços e políticas públicas. $6^{a}$ edição. São Paulo CEDPE- PUC-SP, 2015.

SEMZEZEM, Priscila; ALVES, Jolinda de Moraes Alves. Vulnerabilidade social, abordagem territorial e proteção na política de assistência social SERV. SOC. REV., LONDRINA, V. 16, N.1, P. 143-166, JUL./ DEZ. 2013.

SPOSATI, Aldaíza. Modelo Brasileiro de Proteção Social não Contributiva: concepções fundantes. In: Concepção e gestão da proteção social não contributiva no Brasil. Brasilia: Ministério do Desenvolvimento Social e Combate à Fome, UNESCO, 2009.

VALOURA, Leila de Castro. Paulo Freire, o educador brasileiro autor do termo Empoderamento, em seu sentido transformador. Programa Comunicarte de Residência Social. 2005/2006.

VAN NESS, Daniel. The Shape of Things to Come: A Framework for Thinking about A Restorative Justice System. Presented at the Fourth International Conference on Restorative Justice for Juveniles. 2020. Disponível em: http://www.justicereparatrice.org/www.restorativejustice. org/10fulltext/vanness9/view. Acesso em: 21 mar 2021.

YAZBEK, Maria C. Sistema de proteção social brasileiro: modelo, dilemas e desafios. Brasília: MDS, 2010. ZEHR, Howard. Trocando as lentes: justiça restaurativa para o nosso tempo. Tradução Tônia Van Acker. São Paulo: Palas Atenas, 2008.

ZEHR, Howard. Justiça restaurativa. Tradução: Tônia Van Acker. São Paulo: Palas Athena, 2015. 